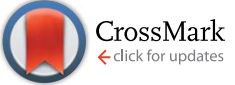

Cite this: Chem. Sci., 2016, 7, 932

\title{
Chirality sensing of tertiary alcohols by a novel strong hydrogen-bonding donor - selenourea $\uparrow$
}

\author{
Guangling Bian, ${ }^{a}$ Shiwei Yang, ${ }^{a}$ Huayin Huang, ${ }^{a}$ Hua Zong, ${ }^{a}$ Ling Song, ${ }^{\text {*a }}$ \\ Hongjun Fan ${ }^{\star b}$ and Xiaoqiang Sun ${ }^{* c}$
}

Chemical sensors are powerful for the fast recognition of chiral compounds. However, the established sensing systems are less effective for chiral tertiary alcohols. The chiral tertiary alcohol group is an important structural unit in natural products and drug molecules, and its enantioselective recognition represents a significant and challenging task. In this paper, a novel type of chiral bisselenourea sensor was first synthesized and used as a strong hydrogen-bonding donor for highly efficient chiral recognition of a diverse range of tertiary alcohols. The obtained sharply split NMR signals are well-distinguishable with a large (up to $0.415 \mathrm{ppm}$ ) chemical shift nonequivalence. The NMR signal of the hydroxyl hydrogen atom was first employed for enantiomeric excess determination of tertiary alcohols, giving accurate results with $<2 \%$ absolute errors. The $2 \mathrm{D}$ NOESY spectra and computational studies suggest that the geometrical differentiation of the formed diastereomeric complexes between the sensor and tertiary alcohols enables the chiral discrimination of the hydroxyl hydrogen signals of the tertiary alcohol in the ${ }^{1} \mathrm{H}$ NMR spectrum.

Received 5th October 2015 Accepted 20th October 2015

DOI: $10.1039 /$ c5sc03780h

www.rsc.org/chemicalscience tertiary centers and can be found in many well-known compounds, for example linalool, bedaquiline, camptothecin, escitalopram, efavirenz, etc. ${ }^{\mathbf{1 1}}$ Chiral recognition of tertiary alcohols is mainly dependent on using time-consuming and expensive chiral chromatography. ${ }^{12}$ Only very few chiral lanthanide shift reagents ${ }^{13}$ and chiral solvating agents (CSA) $)^{8 h-j}$ have been reported as NMR sensors for chiral tertiary alcohols, and the resolved effects were less than satisfactory because of either inherent line broadening ${ }^{\mathbf{6 a , 8 a , 1 4}}$ or a small signal split. Therefore, an accurate and highly efficient chemical sensing system for chiral tertiary alcohols is still highly desirable.

To address this problem, we targeted a chirality sensing system with NMR sensors, employing the proton signal of the hydroxyl group $(\mathrm{O}-\underline{\mathrm{H}})$ attached to the quaternary stereogenic center of a tertiary alcohol. Since the $\mathrm{O}-\mathrm{H}$ group is involved in intermolecular interactions with CSA via hydrogen bonds, the

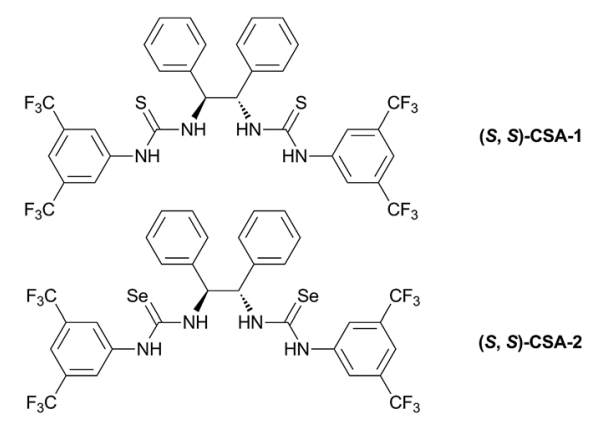

Fig. 1 Structures of bisthiourea and bisselenourea. 
$\mathrm{O}-\underline{\mathrm{H}}$ signal is more easily split. Herein, we report a novel type of sensor, bisselenourea (S,S)-CSA-2 (Fig. 1, right), which could give well-resolved and sharp $\mathrm{O}-\underline{\mathrm{H}}$ signals for the enantiodiscrimination of structurally diverse tertiary alcohols using ${ }^{1} \mathrm{H}$ NMR technology.

\section{Results and discussion}

\section{Molecular design}

A large number of studies has shown that the urea (thiourea) groups of chemical molecules are important recognition sites because they are involved in intermolecular interactions with other molecules via hydrogen bonds. ${ }^{15}$ In the recognition of chiral compounds, the urea (thiourea) groups primarily act as hydrogen bond donors, and their ability to provide a hydrogen bond is an important factor for the success or failure of the recognition. In general, a urea (thiourea) with a stronger $\mathrm{N}-\mathrm{H}$ acidity is a better hydrogen bond donor, which is helpful for improving chiral recognition. Accordingly, we developed a $\mathrm{CF}_{3}-$ substituted bisthiourea with a strong $\mathrm{N}-\mathrm{H}$ acidity (Fig. 1, left, $(S, S)$-CSA-1), which showed excellent enantiodiscrimination for a series of $\alpha$-carboxylic acids based on split $\alpha$-H NMR signals. ${ }^{16}$ However, when used to discriminate several tertiary alcohols, $(S, S)$-CSA-1 gave much smaller splits of the proton signals due to weak intermolecular interactions. To improve the chiral discrimination of chiral alcohols, we conceived that a stronger hydrogen bond donor than $(S, S)$-CSA-1 should facilitate the hydrogen-bonding interactions between CSA and tertiary alcohols.

In order to achieve an outstanding performance for the chiral recognition of tertiary alcohols, selenourea attracted our attention. Selenium has similar properties to sulfur with a larger atomic radius. The larger atomic radius makes selenium able to accommodate more negative charge than sulfur, which could induce a stronger $\mathrm{N}-\mathrm{H}$ acidity of selenoureas. ${ }^{17}$ Therefore, selenourea should be a stronger hydrogen-bonding donor than thiourea. However, the study of selenourea as a proton donor is limited and data on the $\mathrm{N}-\mathrm{H}$ acidity of selenourea is not available in literature. Using diphenyl urea, diphenyl thiourea and diphenyl selenourea as model molecules, we found that the $\mathrm{N}-\mathrm{H} \mathrm{p} K_{\mathrm{a}}^{\mathrm{DMSO}}$ values decrease in the order of diphenyl urea, diphenyl thiourea and diphenyl selenourea, as shown in Table 1 by theoretical calculations. This suggests that selenourea is a stronger hydrogen-bonding donor than thiourea. This result encouraged us to employ selenourea compounds for the chiral recognition of tertiary alcohols. So, we designed and synthesized $(S, S)$-CSA-2, which is an analog of $(S, S)$-CSA-1 (Scheme 1). The calculated $\mathrm{p} K_{\mathrm{a}}^{\text {DMSO }}$ value of $(S, S)$ CSA-2 is significantly less than that of $(S, S)$-CSA-1 (Table 1). $(S, S)$-CSA-2 was expected to give a better performance in the chiral recognition of tertiary alcohols than $(S, S)$-CSA-1.

\section{Test discriminating ability}

With $(S, S)$-CSA-2 in hand, we first compared its enantiomeric discriminating ability with that of $(S, S)$-CSA-1 by testing several tertiary alcohols under the same experimental conditions $(10$
Table 1 The $\mathrm{N}-\mathrm{H}$ pKa values of (thio)urea and selenourea

\begin{tabular}{|c|c|c|}
\hline Compound & $\mathrm{p} K_{\mathrm{a}}^{\mathrm{DMSO}}(\operatorname{exptl})$ & $\mathrm{p} K_{\mathrm{a}}^{\mathrm{DMSO}}(\text { calcd })^{a}$ \\
\hline & 18.7 (ref. 18) & 18.5 \\
\hline & 13.4 (ref. 18) & 13.8 \\
\hline & - & 11.8 \\
\hline$(S, S)$-CSA-1 & - & $9.9^{b}$ \\
\hline$(S, S)-\mathrm{CSA}-2$ & - & $7.5^{c}$ \\
\hline
\end{tabular}

${ }^{a}$ Calculated $\mathrm{p} K_{\mathrm{a}}^{\mathrm{DMSO}}$ values with the use of the relative determination method. 4-Nitrophenol (10.8) was chosen as the reference acid. ${ }^{b} \mathrm{~N}-\mathrm{H}$ of 3,5-bistrifluormethyl aniline of $(S, S)$-CSA-1. ${ }^{c} \mathrm{~N}-\mathrm{H}$ of 3,5bistrifluormethyl aniline of $(S, S)$-CSA-2.

$\mathrm{mM}$ racemic guest and $10 \mathrm{mM}$ host in $\mathrm{CDCl}_{3}$ ) (Table 2). As shown in Table 2, $(S, S)$-CSA-2 does have a better recognition effect than $(S, S)$-CSA-1, in line with our expectation. This result confirms that replacing $S$ with Se does effectively enhance the acidity of $\mathrm{N}-\mathrm{H}$ to facilitate the hydrogen-bonding interactions of the alcohols with $(S, S)$-CSA-2 and improve the chiral recognition. Then, we chose guest A as a model molecule to optimize the discriminating conditions (Table 3). By changing the solvent, a larger (up to $0.052 \mathrm{ppm}) \Delta \Delta \delta$ value was obtained with deuterated benzene, implying that a tighter diastereomeric complex could be formed in a more nonpolar solvent, resulting in a better resolution (Table 3, entries 1-4). Increasing the concentrations of guest A and $(S, S)$-CSA-2 caused the resolution effect to significantly improve because the equilibrium of the diastereomeric complex formation was driven to the right with higher concentrations (Table 3, entries 4-7). The best result was obtained with $30 \mathrm{mM}$ of guest A and $90 \mathrm{mM}$ of $(S, S)$-CSA-2 (Table 3, entry 9). The corresponding $\Delta \Delta \delta$ value is $0.137 \mathrm{ppm}$,
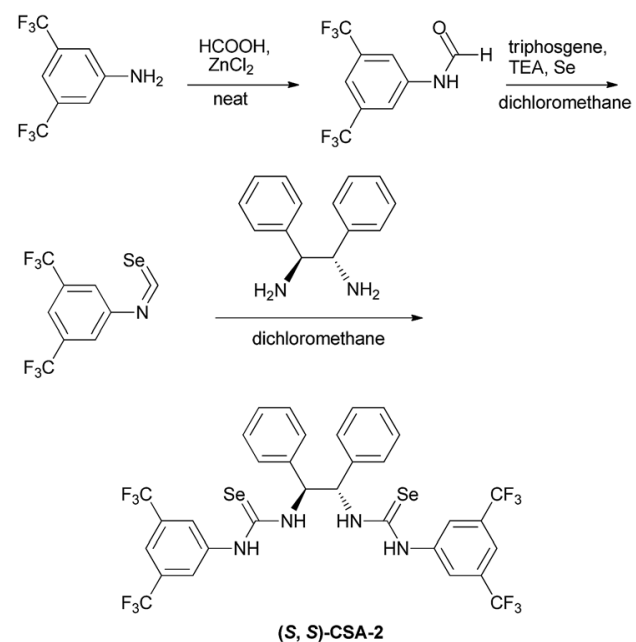

Scheme 1 Synthesis of bisselenourea (S,S)-CSA-2. 
Table 2 Comparison of the discriminating ability of $(S, S)-C S A-2$ and $(S, S)-C S A-1^{a}$

\begin{tabular}{lll}
\hline Entry Guest & Spectrum $^{b}$ & $\Delta \Delta \delta^{c}(\mathrm{ppm})$ \\
\hline
\end{tabular}

1<smiles>CCC(C)(O)c1ccccc1</smiles>

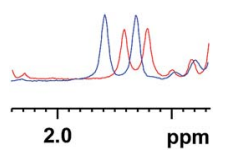

0.027 (blue), 0.020 (red)

2<smiles>CC(C)C(O)(c1ccccc1)c1ccccc1</smiles>

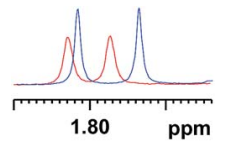

0.043 (blue), 0.028 (red)

3<smiles>CC(O)(c1ccccc1)c1ccc2ccccc2c1</smiles>

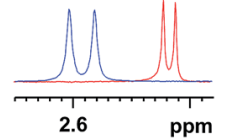

0.022 (blue), 0.012 (red)
${ }^{a}$ All samples were prepared by mixing $1: 1$ of CSAs and guests in NMR tubes $\left(10 \mathrm{mM}\right.$ in $\left.\mathrm{CDCl}_{3}\right) .{ }^{b}$ Red spectra were obtained with $(S, S)$-CSA-1, and blue spectra were obtained with $(S, S)$-CSA-2 by ${ }^{1} \mathrm{H}$ NMR $(400$ $\mathrm{MHz})$ at $25{ }^{\circ} \mathrm{C}$. ${ }^{c}$ Chemical shift non equivalences $(\Delta \Delta \delta)$ of the $\mathrm{O}-\underline{\mathrm{H}} \mathrm{s}$ of guests, red values were obtained with $(S, S)$-CSA-1, and blue values were obtained with $(S, S)$-CSA-2.

Table 3 Optimization of the discriminating conditions for 2-phenyl2-butanol (guest A) by $(S, S)-C S A-2^{a}$

\begin{tabular}{lllll}
\hline & & & & \\
\cline { 3 - 4 } Entry & Solvent & Guest A & $(S, S)$-CSA-2 & $\Delta \Delta \delta^{b}(\mathrm{ppm})$ \\
\hline 1 & $\mathrm{CDCl}_{3}$ & 10 & 10 & 0.027 \\
2 & $\mathrm{DMSO}$ & 10 & 10 & 0 \\
3 & $\mathrm{CD}_{3} \mathrm{COCD}$ & 10 & 0 \\
4 & Benzene $_{3}$ & 10 & 10 & 0.052 \\
5 & Benzene & 20 & 20 & 0.074 \\
6 & Benzene & 30 & 30 & 0.097 \\
7 & Benzene & 40 & 40 & 0.108 \\
8 & Benzene & 30 & 60 & 0.125 \\
$\mathbf{9}$ & Benzene & $\mathbf{3 0}$ & $\mathbf{9 0}$ & $\mathbf{0 . 1 3 7}$
\end{tabular}

${ }^{a}$ Guest A and $(S, S)$-CSA-2 were mixed in the specified solvent $(0.6 \mathrm{~mL})$ and the ${ }^{1} \mathrm{H}$ NMR data were collected on a Bruker Avance $400 \mathrm{MHz}$ spectrometer at $25{ }^{\circ} \mathrm{C} .{ }^{b} \Delta \Delta \delta$ of the $\mathrm{O}-\mathrm{H}$ group of guest A.

which shows enantiodifferentiation of the enantiomers of the racemic guest A clearly. Therefore, the optimized conditions for our further investigations were chosen as follows: $C_{6} D_{6}$ as the solvent with $30 \mathrm{mM}$ of the tertiary alcohol guests and $90 \mathrm{mM}$ of bisselenourea $(S, S)$-CSA-2.

The applicability of these conditions for racemic alcohols with various structures is demonstrated by the data displayed in Table 4. The $\Delta \Delta \delta$ values of the $\mathrm{O}-\underline{\mathrm{H}}$ groups are large enough to give a baseline resolution for all the tested tertiary alcohols ranging from simple to multifunctional ones on a $400 \mathrm{MHz}$ NMR instrument at $25{ }^{\circ} \mathrm{C}$ (Table 4, entries 1-7). Guest C containing a tetrahydronaphthyl group gave well-distinguishable proton signals with a large (up to $0.415 \mathrm{ppm}$ ) $\Delta \Delta \delta$ value. Racemic axially chiral BINOL (guest $\mathrm{H}$ ), containing $\mathrm{sp}^{2} \mathrm{C}-\mathrm{OH}$ and being structurally similar to tertiary alcohols, could also be
Table 4 Measurements of NMR $\Delta \Delta \delta$ of racemic guests in the presence of $(S, S)-C S A-2^{a}$

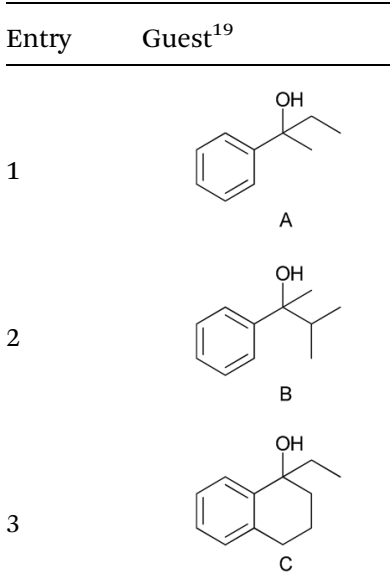

3

Spectrum

$\Delta \Delta \delta(\mathrm{ppm})$

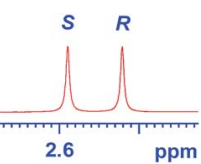

$0.137^{c}$

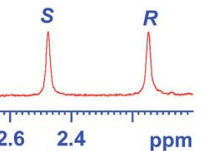

$0.328^{c}$
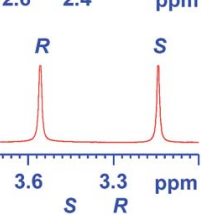

$0.415^{c}$<smiles>CC(O)(c1ccccc1)c1ccc2ccccc2c1</smiles>

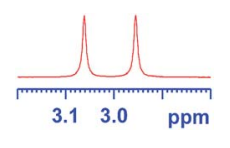

$0.105^{c}$<smiles>CC(O)(C#Cc1ccccc1)c1ccccc1</smiles>

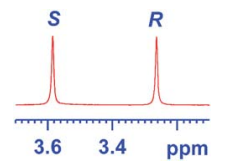

$0.320^{c}$

6
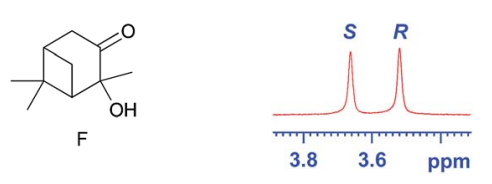

$0.144^{c}$<smiles>O=C([O-])C(O)(C(=O)Nc1ccccc1)c1ccccc1</smiles>

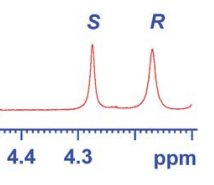

$0.111^{c}$<smiles>Oc1ccc2ccccc2c1-c1c(O)ccc2ccccc12</smiles>

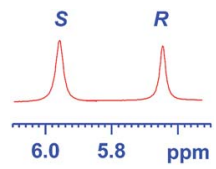

$0.315^{c}$

9<smiles>CC(O)c1ccccc1</smiles>

10<smiles>CC(C)C1CCC(C)C(O)C1</smiles>

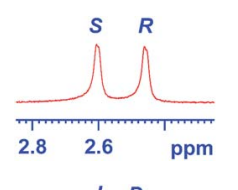

$0.144^{c}$

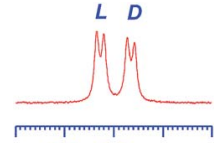

$\begin{array}{lll}2.9 & 2.8 & \text { ppm }\end{array}$<smiles>OC(c1ccccc1)C(F)(F)F</smiles>

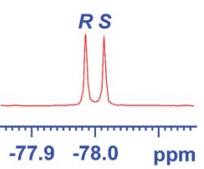

$0.062^{c}$

$0.029^{d}$ 
Table 4 (Contd.)

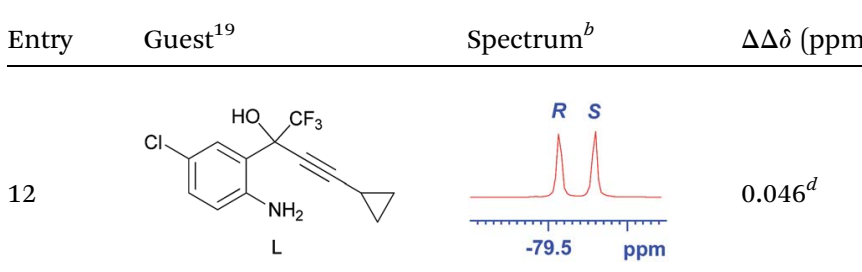

${ }^{a}$ All samples were prepared by mixing $(S, S)$-CSA-2 and the guests in NMR tubes $(30 \mathrm{mM}$ of the guest and $90 \mathrm{mM}$ of $(S, S)$-CSA-2 in $0.6 \mathrm{~mL}$ of $\left.\mathrm{C}_{6} \mathrm{D}_{6}\right) .{ }^{1} \mathrm{H}$ NMR and ${ }^{19} \mathrm{~F}$ NMR data were collected on a Bruker Avance $400 \mathrm{MHz}$ spectrometer at $25{ }^{\circ} \mathrm{C} .{ }^{b}$ The $\mathrm{O}-\underline{\mathrm{H}}$ signals of guests $\mathrm{A}-\mathrm{J}$ and the fluorine signals of guests $\mathrm{K}$ and $\mathrm{L}$; the configuration was determined by comparing with the spectra of nonracemic samples of known configurations. ${ }^{c} \Delta \Delta \delta$ of the $\mathrm{O}-\underline{\mathrm{H}}$ of guests $\mathrm{A}-\mathrm{J} .{ }^{d} \Delta \Delta \delta$ of the fluorine atoms of guests $\mathrm{K}$ and $\mathrm{L}$.

effectively enantiodiscriminated by $(S, S)$-CSA-2 (Table 4, entry 8). Compared with A, although secondary alcohol I lacks one electron-donating ethyl group, its smaller steric hindrance facilitates the intermolecular noncovalent interactions with $(S, S)$-CSA-2 resulting in a similar $\Delta \Delta \delta$ value to A (Table 4 , entry 9). Compared with the $0.062 \mathrm{ppm} \Delta \Delta \delta$ value of aliphatic secondary alcohol $\mathrm{J}$, the much larger $\Delta \Delta \delta$ value $(0.144 \mathrm{ppm})$ of I indicates that pi-pi interactions between the aromatic rings of I and $(S, S)$-CSA-2 contribute to the chiral discrimination (Table 4 entries 9-10). In addition, $(S, S)$-CSA-2 has no proton signals in the middle and high fields of its ${ }^{1} \mathrm{H}$ NMR spectrum (see the ESI $\dagger$ ), and so it does not interfere with the $\mathrm{O}-\underline{\mathrm{H}}$ signals of the guests. Besides ${ }^{1} \mathrm{H}$ NMR spectroscopy, $(S, S)$-CSA-2 could chiral discriminate tertiary alcohols by other heteronuclear NMR spectroscopy methods. For instance, guests $\mathrm{K}$ and $\mathrm{L}$ could be clearly resolved by $(S, S)$-CSA-2 using ${ }^{19} \mathrm{~F}$ NMR spectroscopy (guest $\mathrm{L}$ is a precursor of efavirenz, an important chiral drug used against HIV) (Table 4, entries 11-12).

We further investigated the influences of time and temperature on the chiral discrimination of alcohols using guest I as an example. The results show that time has no influence on the chiral discrimination. Lowering the temperature increases the $\Delta \Delta \delta$ value but has no effect on the ee value (see the ESI $\dagger$ ).

To verify the accuracy of the ee determination method for tertiary alcohols using $(S, S)$-CSA-2, the ee values of several nonracemic samples of guest $\mathrm{F}$ were determined by integration of the O- $\underline{\mathrm{H}}$ signals of guest F. Fig. 2 shows that $(S, S)$-CSA-2 maintains analytical resolution for the tertiary alcohol $\mathrm{F}$ samples over a wide range of ee values. The linear relationship between the NMR determined values (based on the $\mathrm{O}-\underline{\mathrm{H}}$ signals) and the HPLC determined values is excellent. The absolute errors in the ee measurements by NMR and HPLC integrations are within $2 \%$.

\section{Molecular recognition modes}

To understand the nature of the chiral recognition of $(S, S)$-CSA2 for tertiary alcohols, the recognition modes of $(S, S)$-CSA-2 to guest A were studied. We first investigated the stoichiometry of
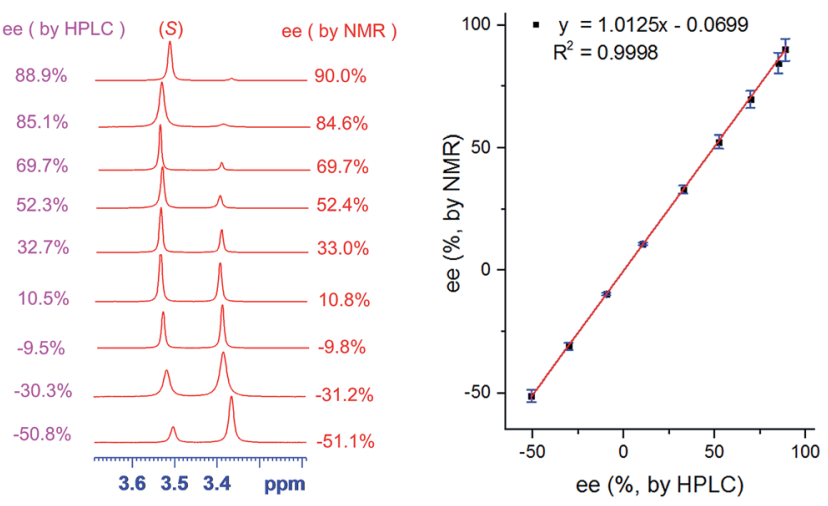

Fig. 2 Selected regions of the ${ }^{1} \mathrm{H}$ NMR spectra of nonracemic guest $F$ (various ee values) with (S,S)-CSA-2 and the linear correlation between the ee values determined by HPLC and NMR (ee values are defined in terms of (S)-F).

the host-guest in the complex by Job plots (see the ESI $\dagger$ ). The Job plots exhibit a maximum at $X=0.5$, indicating $1: 1$ complexation of the host-guest. Then, the binding constants of the $(R)-\mathrm{A} /(S, S)$-CSA-2 complex and $(S)-\mathrm{A} /(S, S)-\mathrm{CSA}-2$ complex were determined by the nonlinear least-squares method (see the ESI $\dagger)$. The larger binding constant of $(S)$-A/ $(S, S)$-CSA-2 suggests that it is a more stable complex than $(R)-\mathrm{A} /(S, S)$-CSA-2 (Table 5$)$.

2D NOESY experiments for the mixture of racemic guest $\mathrm{A}$ and $(S, S)$-CSA-2 show a strong correlation between guest A and $(S, S)$-CSA-2 (Fig. 3), indicating that the intermolecular noncovalent interactions present in the complexes result in a closeness of multiple hydrogen atoms $\left(\mathrm{H}_{\mathrm{k}}, \mathrm{H}_{\mathrm{l}}, \mathrm{H}_{\mathrm{m}}, \mathrm{H}_{\mathrm{R}}\right.$ or $\left.\mathrm{H}_{\mathrm{S}}\right)$ of guest A to $(S, S)$-CSA-2 $\left(\mathrm{H}_{\mathrm{a}}\right.$ and $\left.\mathrm{H}_{\mathrm{d}}\right)$ in space. Among them, $\mathrm{H}_{\mathrm{a}}$ of $(S, S)$-CSA-2 shows strong NOESY correlated signals with guest A. In addition, its chemical shift dramatically moves downfield (see the ESI $\dagger$ ). These results suggest that $\mathrm{H}_{\mathrm{a}}$ is more likely to be the intermolecular interaction site.

Computational modeling studies ${ }^{20}$ show that both $(S)$-A/ $(S, S)$-CSA-2 and $(R)$-A/ $(S, S)$-CSA-2 complexes have hydrogenbonding and pi-pi interactions. As shown in Fig. 4 and Table 6, $(S)$-A/ $(S, S)$-CSA-2 has a relatively shorter hydrogen bond length, a larger calculated binding energy $\Delta G$ and a larger calculated chemical shift of O- $\underline{\mathrm{H}}$ compared to $(R)-\mathrm{A} /(S, S)$-CSA-2, which also indicates that $(S)-\mathrm{A} /(S, S)-\mathrm{CSA}-2$ is more stable. We propose that the preference of $(S)-\mathrm{A} /(S, S)-\mathrm{CSA}-2$ is due to a weaker steric repulsion between $(S)$-A and $(S, S)$-CSA-2 . As shown by the optimized structures, in $(S)$-A/ $(S, S)$-CSA-2, the $\mathrm{CH}_{3}$ group is situated in the bimolecular interacting region, while the larger $\mathrm{C}_{2} \mathrm{H}_{5}$ group is far away. By contrast, in $(R)-\mathrm{A} /(S, S)$-CSA-2, the larger $\mathrm{C}_{2} \mathrm{H}_{5}$ group is situated in the bimolecular interacting region,

Table 5 Binding constants between (S,S)-CSA-2 and guest A

\begin{tabular}{lll}
\hline Host & Guest & $K_{\mathrm{a}}{ }^{a}\left(\mathbf{M}^{-1}\right)$ \\
\hline$(S, S)$-CSA-2 & $(R)$-A & 12.4 \\
$(S, S)$-CSA-2 & $(S)$-A & 26.8
\end{tabular}

${ }^{a}$ The $K_{\mathrm{a}}$ values were calculated by the nonlinear least-squares method. 


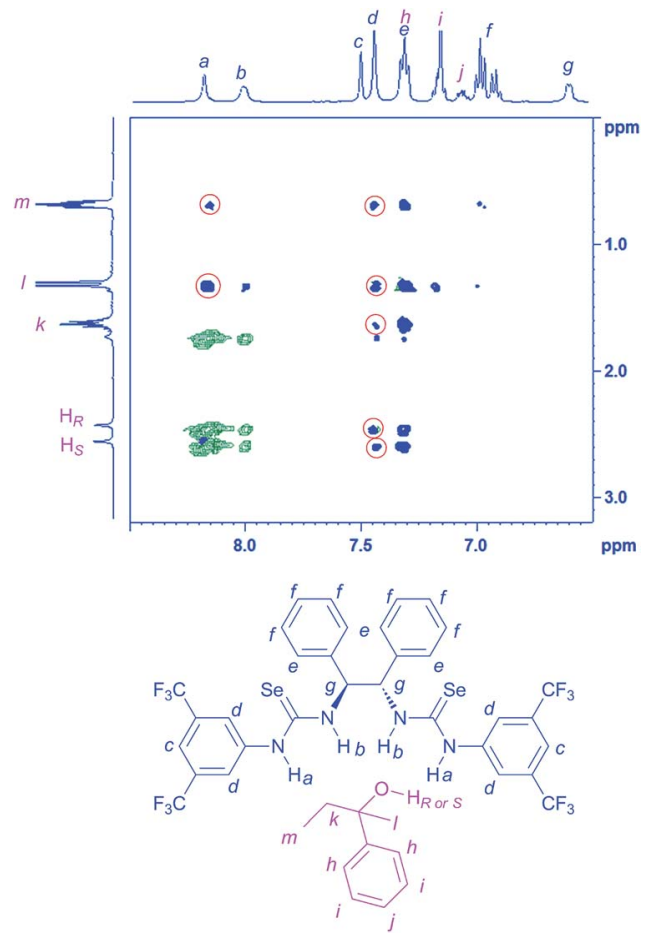

Fig. 3 A portion of the $500 \mathrm{MHz} 2 \mathrm{D}$ NOESY spectrum of a solution of racemic guest $A(100 \mathrm{mM}) /(\mathrm{S}, \mathrm{S})-\mathrm{CSA}-2(100 \mathrm{mM})$ in $\mathrm{C}_{6} \mathrm{D}_{6}$ at $25^{\circ} \mathrm{C}$ (intermolecular correlations of guest $A$ to $(S, S)-C S A-2$ are circled in red).

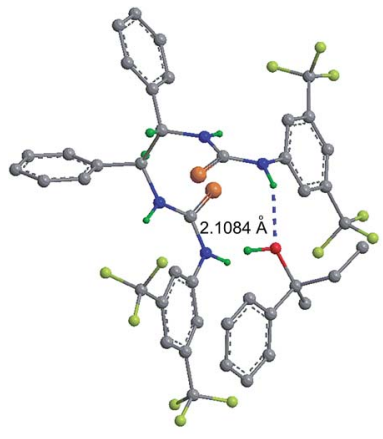

$(S)-A+(S, S)-C S A-2$

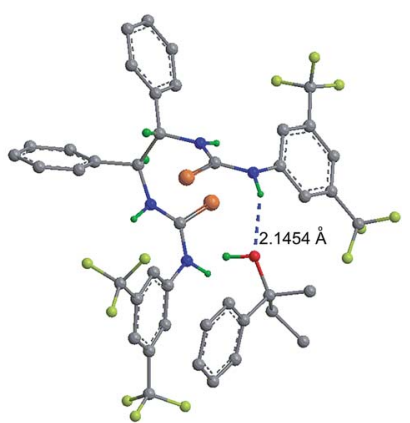

$(R)-A+(S, S)-C S A-2$
Fig. 4 Space-filling representations of the complexes.

Table 6 Calculated $\delta$ values of guest $A$ and binding energies between $(S, S)-C S A-2$ and guest A

\begin{tabular}{lll}
\hline Guest & $\delta(\text { calcd })^{a}(\mathrm{ppm})$ & $\begin{array}{l}-\Delta G \\
\left(\mathrm{kcal} \mathrm{mol}^{-1}\right)\end{array}$ \\
\hline$(R)$-A & 2.17 & 15.8 \\
$(S)$-A & 2.54 & 18.0
\end{tabular}

${ }^{a}$ The chemical shift of $\mathrm{O}-\underline{\mathrm{H}}$ of guest $\mathrm{A}$ in the guest $\mathrm{A} /(S, S)$-CSA-2 complex. which could result in stronger steric repulsion. Therefore, $(S)$-A/ $(S, S)$-CSA-2 is a sterically preferred complex compared to $(R)-\mathrm{A} /$ $(S, S)$-CSA-2.

On the basis of the above experimental investigations, the mechanism of the chiral discrimination of tertiary alcohol A with $(S, S)$-CSA-2 was proposed. Each enantiomer of racemic guest A interacts with chiral $(S, S)$-CSA-2 to form a $1: 1$ diastereomeric complex via noncovalent interactions. The spatial differentiations of the two $\mathrm{O}-\mathrm{H}$ groups in the formed diastereomeric complexes cause a split of the $\mathrm{O}-\underline{\mathrm{H}}$ signals of the two enantiomers of racemic guest A. (S)-A combines with $(S, S)$-CSA-2 more tightly than $(R)$-A, which causes the chemical shift of $\mathrm{O}-\underline{\mathrm{H}}$ of $(S)$-A to be moved more downfield with a larger $\delta$ value.

\section{Experimental}

\section{Materials and methods}

Diphenyl urea (TCI Co. Ltd.), diphenyl thiourea (TCI Co. Ltd.), BINOL (TCI Co. Ltd.), 1-phenylethanol (TCI Co. Ltd.), $(1 R, 2 R, 5 R)-(+)-2$-hydroxy-3-pinanone (TCI Co. Ltd.), $(1 S, 2 S, 5 S)$ (-)-2-hydroxy-3-pinanone (TCI Co. Ltd.), $(1 S, 2 R, 5 S)-(+)-$ menthol (Adamas-beta $\left.{ }^{8}\right),(1 R, 2 S, 5 R)-(-)-m e n t h o l$ (Adamas-beta $\left.\AA\right), 3,5-$ di(trifluoromethyl)aniline (Adamas-beta $\left.{ }^{\circledR}\right)$, and $(S, S)-1,2-$ diphenylethane-1,2-diamine (TCI Co. Ltd.) were used as received. Other tertiary alcohols and isoselenocyanate were synthesized by following the literature procedure. ${ }^{21}$

\section{Theoretical calculations}

All electronic structure calculations were performed with the Gaussian09 program. ${ }^{20}$ The $\mathrm{p} K_{\mathrm{a}}^{\mathrm{DMSO}}$ values were calculated with the use of the relative determination method, and 4-nitrophenol (10.8) was chosen as the reference. ${ }^{18}$ The gas-phase acidities of all compounds were calculated using the M06-2X/ccpVTZ method, the solvent effects were evaluated with the IEFPCM model, and the $\mathrm{p} K_{\mathrm{a}}$ values of all compounds in DMSO were calculated by $\Delta \mathrm{p} K_{\mathrm{a}}=\Delta G / R T\left(\Delta \mathrm{p} K_{\mathrm{a}}\right.$ and $\Delta G$ are the $\mathrm{p} K_{\mathrm{a}}$ and free energy differences between the given compound and the reference molecule). Computational modeling studies were performed with the Gaussian09 program. ${ }^{20}$ The geometries of the ternary complexes were optimized using the molecular mechanics method initially and then the DFT method at the M06-2X/cc-pVTZ level of theory. All geometry optimizations were carried out in the gas phase. Binding energies and NMR chemical shifts were calculated at the M06-2X/cc-pVTZ level of theory in benzene solvent with the GIAO method (solvent effects were evaluated with the IEFPCM model).

\section{General procedure for the synthesis of $(S, S)$-CSA-2}

3,5-Bis(trifluoromethyl)aniline (10 g, $43.6 \mathrm{mmol})$ and anhydrous $\mathrm{ZnCl}_{2}(1.186 \mathrm{~g}, 8.7 \mathrm{mmol})$ were taken in a $50 \mathrm{~mL}$ round bottomed flask. To the mixture, formic acid $(10 \mathrm{~mL}, 267 \mathrm{mmol})$ was added drop-wise with constant stirring for $10 \mathrm{~min}$. This mixture was heated at $70{ }^{\circ} \mathrm{C}$ for $5 \mathrm{~h}$ and the progress of the reaction was monitored by TLC. When the reaction was completed, the mixture was cooled to room temperature and diluted with ethyl acetate $(40 \mathrm{~mL})$. The organic layer was washed 
with water and brine, and dried over anhydrous $\mathrm{Na}_{2} \mathrm{SO}_{4}$. The solvent was removed under reduced pressure and the resulting crude product was purified by recrystallization (in ethanol) to obtain the corresponding $N$-formyl derivative $(10.66 \mathrm{~g}, 95 \%, \mathrm{mp}$ 121-122 ${ }^{\circ} \mathrm{C}$, lit. ${ }^{22} 124-125{ }^{\circ} \mathrm{C}$ ). A solution of triphosgene (692 $\mathrm{mg}, 2.33 \mathrm{mmol})$ in dry dichloromethane $(5 \mathrm{~mL})$ was added dropwise under Ar over a period of 1 hour to a refluxing mixture of formamide ( $1 \mathrm{~g}, 3.89 \mathrm{mmol})$, TEA $(2.25 \mathrm{~mL}, 15.56 \mathrm{mmol})$, and 4 A molecular sieves $(2 \mathrm{~g})$ in dry dichloromethane $(10 \mathrm{~mL})$. After the addition, the resulting mixture was refluxed for 4 hours and then black selenium powder (768 $\mathrm{mg}, 9.72 \mathrm{mmol}$ ) was added and the mixture was refluxed overnight in the dark. Then, the mixture was cooled to room temperature and filtered. The filtrate was collected and concentrated to give a residue, which was purified by column chromatography (eluting with dry hexane) to afford isoselenocyanate $(0.49 \mathrm{~g}, 40 \%)$. Caution, this isoselenocyanate is best used directly after separation because it is not very stable and must be stored in the dark.

3,5-Bis(trifluoromethyl)phenyl isoselenocyanate $(0.64 \mathrm{~g}, 2$ $\mathrm{mmol})$ was added to a solution of $(S, S)$-1,2-diphenylethane-1,2diamine $(0.21 \mathrm{~g}, 1 \mathrm{mmol})$ in dry dichloromethane $(15 \mathrm{~mL})$. The solution was stirred overnight at room temperature in the dark. After completion, dry hexane $(100 \mathrm{~mL})$ was added dropwise. The solution was stirred for another 3 hours at room temperature and this produced a lot of white solid, which was filtered off, washed with hexane and dried under vacuum to afford $(S, S)$-CSA$2(0.81 \mathrm{~g}, 95 \%)$. Mp $165-166{ }^{\circ} \mathrm{C} ;[\alpha]_{30}^{\mathrm{D}}=31.8 \mathrm{~g}$ per $100 \mathrm{~mL}(c=1.0$ in $\mathrm{CHCl}_{3}$ ). ${ }^{1} \mathrm{H}$ NMR $\left(400 \mathrm{MHz}, \mathrm{CDCl}_{3}\right): \delta=8.84$ (br s, 2H), 7.95 (br s, 2H), 7.73-7.67 (m, 6H), 7.40-7.20 (m, 10H), $6.17(\mathrm{~s}, 2 \mathrm{H})$ ppm; ${ }^{13} \mathrm{C}$ NMR $\left(100 \mathrm{MHz}, \mathrm{CDCl}_{3}\right): \delta=179.9,138.1,136.4,133.9$, 133.6, 133.2, 132.9, 129.3, 128.9, 127.8, 126.8, 124.8, 124.1, 121.4, $120.7,118.7,67.6 \mathrm{ppm} ;{ }^{77} \mathrm{Se} \mathrm{NMR}\left(95 \mathrm{MHz}, \mathrm{CDCl}_{3}\right): \delta=247 \mathrm{ppm}$; ESI-MS: calcd for $\mathrm{C}_{32} \mathrm{H}_{22} \mathrm{~F}_{12} \mathrm{~N}_{4} \mathrm{Se}_{2}+\mathrm{H} 851.0062$, found 851.0073.

\section{General spectroscopic methods for the chiral discrimination of guests}

$18 \mu \mathrm{mol}$ of the guests and $54 \mu \mathrm{mol}$ of $(S, S)$-CSA- 2 were mixed in $0.6 \mathrm{~mL}$ of $\mathrm{C}_{6} \mathrm{D}_{6}$, and the ${ }^{1} \mathrm{H}$ NMR data were collected on a Bruker Avance $400 \mathrm{MHz}$ spectrometer at $25^{\circ} \mathrm{C}$.

\section{Conclusions}

A chiral bisselenourea was rationally designed and synthesized to serve as a highly efficient NMR sensor for the enantiodiscrimination of various tertiary alcohols. The method employed the sharply split NMR signals of the hydroxyl hydrogen atoms for ee determination, giving accurate results with $<2 \%$ absolute errors. The study of the chiral resolution mechanism suggests that the geometrical differentiation of the formed diastereomeric complexes enables chiral discrimination of the hydroxyl hydrogen signals of tertiary alcohols in ${ }^{1} \mathrm{H}$ NMR spectra. This method can give well-resolved and sharp signals of the hydroxyl hydrogen atoms of tertiary alcohols with a large chemical shift nonequivalence. Due to the lack of proton signals of this bisselenourea in the middle and high fields of the ${ }^{1} \mathrm{H}$ NMR spectrum, it does not interfere with the hydroxyl hydrogen signals of tertiary alcohols. So, it is especially suitable for chiral discrimination and ee determination of tertiary alcohols.

\section{Acknowledgements}

The authors gratefully acknowledge the financial support from The Key Laboratory of Coal to Ethylene Glycol and Its Related Technology, National Natural Science Foundation of China (No. 21173212, 21207131), and Fujian Institute of Research on the Structure of Matter, Chinese Academy of Sciences.

\section{Notes and references}

1 (a) Z. Huang, S. Yu, K. Wen, X. Yu and L. Pu, Chem. Sci., 2014, 5, 3457-3462; (b) P. Metola, E. V. Anslyn, T. D. James and S. D. Bull, Chem. Sci., 2012, 3, 156-161; (c) T. Miyabe, H. Iida, A. Ohnishi and E. Yashima, Chem. Sci., 2012, 3, 863-867; (d) W. Wei, K. Qu, J. Ren and X. Qu, Chem. Sci., 2011, 2, 2050-2056.

2 (a) X. Zhang, J. Yin and J. Yoon, Chem. Rev., 2014, 114, 49184959; (b) L. Pu, Acc. Chem. Res., 2012, 45, 150-163; (c) G. A. Hembury, V. V. Borovkov and Y. Inoue, Chem. Rev., 2008, 108, 1-73.

3 (a) H. H. Jo, C.-Y. Lin and E. V. Anslyn, Acc. Chem. Res., 2014, 47, 2212-2221; (b) C. Wolf and K. W. Bentley, Chem. Soc. Rev., 2013, 42, 5408-5424.

4 (a) X. Mei and C. Wolf, J. Am. Chem. Soc., 2006, 128, 1332613327; (b) P. Zhang and C. Wolf, Chem. Commun., 2013, 49, 7010-7012.

5 (a) K. Wen, S. Yu, Z. Huang, L. Chen, M. Xiao, X. Yu and L. Pu, J. Am. Chem. Soc., 2015, 137, 4517-4524; (b) C. Wang, E. Wu, X. Wu, X. Xu, G. Zhang and L. Pu, J. Am. Chem. Soc., 2015, 137, 3747-3750; (c) T. A. Feagin, D. P. V. Olsen, Z. C. Headman and J. M. Heemstra, J. Am. Chem. Soc., 2015, 137, 4198-4206; (d) K. W. Bentley and C. Wolf, J. Am. Chem. Soc., 2013, 135, 12200-12203.

6 For selected reviews on chiral discrimination using NMR sensors: (a) D. Parker, Chem. Rev., 1991, 91, 1441-1457; (b) T. J. Wenzel, Discrimination of chiral compounds using NMR spectroscopy, Wiley, 2007; (c) T. J. Wenzel and C. D. Chisholm, Prog. Nucl. Magn. Reson. Spectrosc., 2011, 59, 1-63; (d) G. Uccello-Barretta, F. Balzano and P. Salvadori, Curr. Pharm. Des., 2006, 12, 4023-4045; (e) J. Labuta, J. P. Hill, S. Ishihara, L. Hanykova and K. Ariga, Acc. Chem. Res., 2015, 48, 521-529.

7 For selected publications on chiral NMR sensors for carboxylic acids: (a) S. K. Mishra and N. Suryaprakash, $R S C$ $A d v .$, 2015, 5, 67277-67283; (b) H.-T. Feng, X. Zhang and Y.-S. Zheng, J. Org. Chem., 2015, 80, 8096-8101; (c) A. E. Sheshenev, E. V. Boltukhina, A. A. Grishina, I. Cisarova, I. M. Lyapkalo and K. K. Hii, Chem.-Eur. J., 2013, 19, 8136-8143; (d) M. Perez-Trujillo, E. Monteagudo and T. Parella, Anal. Chem., 2013, 85, 10887-10894; (e) D. Kumari, P. Bandyopadhyay and N. Suryaprakash, J. Org. Chem., 2013, 78, 2373-2378; (f) S. R. Chaudhari and N. Suryaprakash, New J. Chem., 2013, 37, 4025-4030; $(g)$ F. Cuevas, P. Ballester and M. A. Pericas, Org. Lett., 2005, 7, 
5485-5487; (h) D. Yang, X. Li, Y.-F. Fan and D.-W. Zhang, J. Am. Chem. Soc., 2005, 127, 7996-7997; (i) A. Gualandi, S. Grilli, D. Savoia, M. Kwit and J. Gawronski, Org. Biomol. Chem., 2011, 9, 4234-4241; (j) M. Hernandez-Rodriguez and E. Juaristi, Tetrahedron, 2007, 63, 7673-7678; ( $k$ ) Q. Ma, M. Ma, H. Tian, X. Ye, H. Xiao, L.-h. Chen and X. Lei, Org. Lett., 2012, 14, 5813-5815; (l) T. P. Quinn, P. D. Atwood, J. M. Tanski, T. F. Moore and J. F. Folmer-Andersen, J. Org. Chem., 2011, 76, 10020-10030; (m) M. Durmaz, M. Yilmaz and A. Sirit, Org. Biomol. Chem., 2011, 9, 571-580.

8 For selected publications on chiral NMR sensors for alcohols: (a) L. M. Sweeting, D. C. Crans and G. M. Whitesides, J. Org. Chem., 1987, 52, 2273-2276; (b) I. Pal, S. R. Chaudhari and N. R. Suryaprakash, Magn. Reson. Chem., 2015, 53, 142-146; (c) C. Rosini, G. Uccello-Barretta, D. Pini, C. Abete and P. Salvadori, J. Org. Chem., 1988, 53, 4579-4581; (d) G. Uccello-Barretta, D. Pini, A. Mastantuono and P. Salvadori, Tetrahedron: Asymmetry, 1995, 6, 1965-1972; (e) d. B.-H. C. von, A. K. Beck, U. Lengweiler and D. Seebach, Helv. Chim. Acta, 1992, 75, 438-441; (f) S. H. Wilen, J. Z. Qi and P. G. Williard, J. Org. Chem., 1991, 56, 485-487; $(g)$ L. S. Moon, M. Pal, Y. Kasetti, P. V. Bharatam and R. S. Jolly, J. Org. Chem., 2010, 75, 5487-5498; (h) L. S. Moon, R. S. Jolly, Y. Kasetti and P. V. Bharatam, Chem. Commun., 2009, 1067-1069; (i) C. Wolf, A. M. Cook and J. E. Dannatt, Tetrahedron: Asymmetry, 2014, 25, 163-169; (j) A. Iuliano, G. Uccello-Barretta and P. Salvadori, Tetrahedron: Asymmetry, 2000, 11, 1555-1563.

9 For selected publications on chiral NMR sensors for various chiral compounds: (a) C. F. Dignam, J. J. Zopf, C. J. Richards and T. J. Wenzel, J. Org. Chem., 2005, 70, 8071-8078; (b) A. Lakshmipriya, S. R. Chaudhari and N. Suryaprakash, Chem. Commun., 2015, 51, 13492-13495; (c) N. Jain, R. B. Patel and A. V. Bedekar, RSC Adv., 2015, 5, 4594345955; (d) I. Pal, S. R. Chaudhari and N. Suryaprakash, New J. Chem., 2014, 38, 4908-4912; (e) A. Couffin, O. Thillaye du Boullay, M. Vedrenne, C. Navarro, B. Martin-Vaca and D. Bourissou, Chem. Commun., 2014, 50, 5997-6000; $(f)$ T. Ema, D. Tanida and T. Sakai, J. Am. Chem. Soc., 2007, 129, 10591-10596; (g) T. Ema, D. Tanida and T. Sakai, Org. Lett., 2006, 8, 3773-3775; (h) G. Uccello-Barretta, A. Iuliano, E. Franchi, F. Balzano and P. Salvadori, J. Org. Chem., 1998, 63, 9197-9203; (i) R. Schwenninger, J. Schlogl, J. Maynollo, K. Gruber, P. Ochsenbein, H.-B. Burgi, R. Konrat and B. Krautler, Chem.-Eur. J., 2001, 7, 2676-2686; (j) M. PerezTrujillo, I. Maestre, C. Jaime, A. Alvarez-Larena, J. F. Piniella and A. Virgili, Tetrahedron: Asymmetry, 2005, 16, 3084-3093; ( $k$ ) A. Port, A. Virgili, A. Alvarez-Larena and J. F. Piniella, Tetrahedron: Asymmetry, 2000, 11, 3747-3757; (l) G. Uccello-Barretta, F. Mirabella, F. Balzano and P. Salvadori, Tetrahedron: Asymmetry, 2003, 14, 1511-1516; (m) S. Tabassum, M. A. Gilani and R. Wilhelm, Tetrahedron: Asymmetry, 2011, 22, 1632-1639; (n) J. Omelańczuk and M. Mikolajczyk, Tetrahedron: Asymmetry, 1996, 7, 2687-2694; (o) Y. Zhao and T. M. Swager, J. Am. Chem. Soc., 2015, 137, 3221-3224.
10 A. Alexakis, S. Mutti and P. Mangeney, J. Org. Chem., 1992, 57, 1224-1237.

11 (a) M. Mueller, ChemBioEng Rev., 2014, 1, 14-26; (b) P. G. Cozzi, R. Hilgraf and N. Zimmermann, Eur. J. Org. Chem., 2007, 2007, 5969-5994; (c) C. Garcia and V. S. Martin, Curr. Org. Chem., 2006, 10, 1849-1889; (d) S. V. Pronin, C. A. Reiher and R. A. Shenvi, Nature, 2013, 501, 195-199.

12 (a) N. M. Maier and G. Uray, J. Chromatogr. A, 1996, 732, 215230; (b) A. Kunath, E. Hoeft, H. J. Hamann and J. Wagner, J. Chromatogr. A, 1991, 588, 352-355; (c) B. Koppenhoefer and H. Allmendinger, Chromatographia, 1986, 21, 503-508.

13 (a) M. D. Johnston Jr, B. L. Shapiro, M. J. Shapiro, T. W. Proulx, A. D. Godwin and H. L. Pearce, J. Am. Chem. Soc., 1975, 97, 542-554; (b) W. Huang and L. Zhang, Acta Chim. Sin., 1989, 7, 183-189; (c) M.-C. Blanc, P. Bradesi and J. Casanova, Magn. Reson. Chem., 2005, 43, 176-179.

14 (a) H. C. Aspinall, Chem. Rev., 2002, 102, 1807-1850; (b) R. E. Lenkinski and J. Reuben, J. Magn. Reson., 1976, 21, 47-56. 15 (a) Z. Zhang and P. R. Schreiner, Chem. Soc. Rev., 2009, 38, 1187-1198; (b) A.-F. Li, J.-H. Wang, F. Wang and Y.-B. Jiang, Chem. Soc. Rev., 2010, 39, 3729-3745; (c) T. R. Kelly and M. H. Kim, J. Am. Chem. Soc., 1994, 116, 7072-7080.

16 (a) G. Bian, H. Fan, S. Yang, H. Yue, H. Huang, H. Zong and L. Song, J. Org. Chem., 2013, 78, 9137-9142; (b) G. Bian, H. Fan, H. Huang, S. Yang, H. Zong, L. Song and G. Yang, Org. Lett., 2015, 17, 1369-1372.

17 F. G. Bordwell, D. J. Algrim and J. A. Harrelson, J. Am. Chem. Soc., 1988, 110, 5903-5904.

18 G. Jakab, C. Tancon, Z. Zhang, K. M. Lippert and P. R. Schreiner, Org. Lett., 2012, 14, 1724-1727.

19 Guest $(R)-\mathrm{F}$ is commercial $(1 R, 2 R, 5 R)-(+)-2$-hydroxy-3pinanone, $(S)$-F is commercial $(1 S, 2 S, 5 S)-(-)-2$-hydroxy-3pinanone, $\mathrm{D}-\mathrm{K}$ is commerical $(1 S, 2 R, 5 S)-(+)-$ Menthol and $\mathrm{L}-\mathrm{K}$ is commercial $(1 R, 2 S, 5 R)-(-)$-Menthol.

20 M. J. T. G. W. Frisch, H. B. Schlegel, G. E. Scuseria, M. A. Robb, J. R. Cheeseman, G. Scalmani, V. Barone, B. Mennucci, G. A. Petersson, H. Nakatsuji, M. Caricato, X. Li, H. P. Hratchian, A. F. Izmaylov, J. Bloino, G. Zheng, J. L. Sonnenberg, M. Hada, M. Ehara, K. Toyota, R. Fukuda, J. Hasegawa, M. Ishida, T. Nakajima, Y. Honda, O. Kitao, H. Nakai, T. Vreven Jr J. A. Montgomery, J. E. Peralta, F. Ogliaro, M. Bearpark, J. J. Heyd, E. Brothers, K. N. Kudin, V. N. Staroverov, R. Kobayashi, J. Normand, K. Raghavachari, A. Rendell, J. C. Burant, S. S. Iyengar, J. Tomasi, M. Cossi, N. Rega, J. M. Millam, M. Klene, J. E. Knox, J. B. Cross, V. Bakken, C. Adamo, J. Jaramillo, R. Gomperts, R. E. Stratmann, O. Yazyev, A. J. Austin, R. Cammi, C. Pomelli, J. W. Ochterski, R. L. Martin, K. Morokuma, V. G. Zakrzewski, G. A. Voth, P. Salvador, J. J. Dannenberg, S. Dapprich, A. D. Daniels, Ö. Farkas, J. B. Foresman, J. V. Ortiz, J. Cioslowski and D. J. Fox, Gaussian 09, Revision A.1, Gaussian, Inc., Wallingford CT, 2009.

21 Ó. López, S. Maza, V. Ulgar, I. Maya and J. G. FernándezBolaños, Tetrahedron, 2009, 65, 2556-2566.

22 G. Pettit, M. Kalnins, T. Liu, E. Thomas and K. Parent, J. Org. Chem., 1961, 26, 2563-2566. 